\title{
Um estudo focado na relação entre design e materiais
}

\section{A study focused on the relationship between design and materials}

\author{
CALEGARI, Eliana Paula I Graduanda em Desenho Industrial \\ Universidade Federal do Rio Grande do Sul I UFRGS \\ elianapaulac@gmail.com
}

\section{OLIVEIRA, Branca Freitas de I Pós Doutora}

Universidade Federal do Rio Grande do Sul I UFRGS

branca@ufrgs.br

\begin{abstract}
Resumo
O presente trabalho configura-se no contexto do design de produto e materiais, tendo por objetivo verificar a relação entre eles. Desta forma, é realizada uma pesquisa exploratória de cunho bibliográfico sobre o tema, a fim de averiguar esta relação. De tal modo, como principais bases teóricas para o desenvolvimento do artigo, são utilizadas obras de George M. Beylerian e Andrew Dent, Maurizio Ferrante e Yuri Walter, Mike Ashby e Kara Johnson. Como principal resultado da reflexão sobre os estudos abordados neste trabalho, cita-se a direta relação entre o design de produto e os materiais, pois em primeira instância estes materializam os produtos projetados. Além disso, podem promover o design inovador, a comunicação e a melhoria da qualidade de vida dos seres humanos.
\end{abstract}

Palavras-Chave: Design de produto. Materiais. Processo de design. Seleção de materiais.

\section{Abstract}

This work is set in the context of product design and materials and the goal is to investigate the relationship between them. Thus, an exploratory bibliographical review on the subject is performed, in order to investigate this relationship. Such as major theoretical basis for the development of the present article works of George M. Beylerian and Andrew Dent, Maurizio Ferrante and Yuri Walter, Mike Ashby and Kara Johnson are utilized. The main result of the reflection on the studies discussed in this work cites the direct relationship between product design and materials, as at the first instance they materialize the designed products. Also, materials can promote the innovative design, communication, and improving the quality of life of human beings.

Keywords: Product design. Materials. Design process. Material selection. 


\title{
INTRODUC̣ÃO
}

O designer de produto concebe ideias, conceitos, desenhos e projetos que são concretizados através dos materiais. Ashby e Johnson (2010) consideram que os materiais são a matéria-prima do design, e comentam que através da história, ditaram as oportunidades e os limites do design. Os autores citam épocas históricas para enfatizar a importância dos materiais, em que expõem as idades (eras) que levam os nomes dos principais materiais utilizados, como a Idade da Pedra, do Bronze, do Ferro, do Plástico, e hoje, do Silício. Ainda, explicam que nos dias atuais é a idade de uma imensa gama de materiais e das combinações que eles permitem, e que nunca houve uma era na qual a evolução dos materiais tenha sido mais rápida e o âmbito de suas propriedades mais variado, segundo os autores:

\begin{abstract}
Vivemos em um mundo de materiais. São os materiais que dão substância a tudo que vemos e tocamos. Nossa espécie - Homo sapiens - é diferente das outras, talvez mais significativamente pela habilidade de projetar - produzir "coisas" a partir de materiais - e pela capacidade de enxergar mais em um objeto do que apenas a sua aparência. Objetos podem ter significado, despertar associações ou ser signos de ideias mais abstratas. Objetos projetados, tanto simbólicos quanto utilitários, precedem qualquer linguagem registrada - e nos dão a mais antiga evidência de uma sociedade cultural e do raciocínio simbólico. (ASHBY; JOHNSON, 2010, p. 3)
\end{abstract}

Sendo assim, materiais como a madeira, a pedra, o osso e a terra foram essenciais para a sobrevivência da humanidade por vários milênios. Desta forma, o desenvolvimento da história humana aponta que os materiais são a base importante e guia no processo de desenvolvimento da sociedade. A maioria dos que são considerados modernos hoje, nasceram no início do século 20, principalmente criados por engenheiros, metalúrgicos e cientistas. A pesquisa em materiais que procura a melhoria e o desenvolvimento de novos materiais é quase tão antiga quanto à própria humanidade, porém, neste momento é considerada verdadeiramente de ponta, (BEYLERIAN; DENT, 2007).

Com o avanço da ciência e da tecnologia, surgiram e continuam surgindo inúmeros novos materiais. Existem aproximadamente 100 mil materiais, essa gama permite que o design seja inovador a partir da exploração imaginativa dos novos e aprimorados materiais, (ASHBY; JONHSON, 2010). Conforme a 
terceira edição do Manual de Oslo, melhoramentos significativos em produtos podem ocorrer através de mudanças em materiais empregados que aprimoram seu desempenho.

Neste contexto, este artigo tem como objetivo verificar a relação existente entre o design e materiais. Para isso, como procedimento metodológico, é realizada uma pesquisa exploratória de cunho bibliográfico em publicações da área acerca da temática do design e materiais e da seleção de materiais.

\section{O Design de produto e suas inferências}

O design de produtos é responsável pela materialização de objetos que medeiam o cotidiano dos seres humanos. Santos (2005), defende que design é o processo que envolve desde o planejamento até a viabilização da produção e está inserido em estruturas sociais que o influencia nos níveis econômico, tecnológico e cultural. Desta maneira, os objetos podem ser considerados produtos culturais na medida em que "são projetados e produzidos para sustentar as práticas sociais vigentes, podendo também contribuir para a transformação e reelaboração simbólica destas mesmas práticas" (SANTOS, 2005, p. 15). Já International Council of Societies of Industrial Design (2005) define o design como um processo criativo cujo objetivo é estabelecer qualidades multifacetadas para objetos, processos, serviços e seus sistemas em todo o ciclo de vida.

Cardoso (1998) aborda o design do ponto de vista antropológico quando afirma que ele é uma entre diversas atividades projetuais, como as artes, o artesanato, a arquitetura, a engenharia e outras que visam atribuir existência concreta e autônoma a ideias abstratas e subjetivas. Assim, o design configura a comunicação e contribui na constituição identitária, pois quando produtos são comprados e usados eles assumem caráter simbólico e transmitem significados e valores, (SCHNEIDER, 2010). Como esta relação ocorre em um contexto sociocultural, o autor explica que o design é "um instrumento para a produção de realidade social", (SCHNEIDER, 2010, p. 12). Deste modo, no processo de configuração dos produtos são atribuídos significados e valores construídos socialmente.

Nesta perspectiva, as decisões tomadas pelo designer no ato de projetar, como os conceitos e elementos materiais não são neutras, pois ele está inserido em um contexto sociocultural e suas escolhas são influenciadas pelas práticas e valores sociais. Assim, quando as pessoas apropriam-se de objetos, também estão apropriando-se dos significados a eles associados, além de atribuir novos, 
como os que não foram planejados pelo designer, pois segundo Santos (2005) os significados são passíveis de transformações, na medida em que estão intrinsecamente ligados às dinâmicas sociais. Desta maneira, é conveniente que o designer leve em consideração questões relacionadas às práticas e valores socialmente construídos além da viabilidade produtiva dos produtos.

\section{O processo de design}

Conforme Rozenfeld et al. (2006) o desenvolvimento de produto consiste em uma série de atividades por meio das quais busca-se especificar o projeto de um produto e seu processo de produção, para que seja passível de fabricação, levando em consideração as necessidades do mercado e as possibilidades e restrições tecnológicas. Segundo o autor, o desenvolvimento de produto envolve atividades após o seu lançamento, em que podem ser realizadas eventuais mudanças necessárias com vistas a melhorar o produto.

De acordo com o autor, devido à complexidade inerente do desenvolvimento de produto, é necessária a utilização de um modelo de referência para esta atividade, que busque adequar o processo às necessidades do projetista, pois, um processo não estruturado pode torná-lo inviável para a obtenção de especificações de projeto. Além da complexidade, as causas que estabelecem os métodos de desenvolvimento de produto estão relacionadas com a velocidade com que a grande quantidade de informações precisam ser manipuladas e os problemas que surgem no decorrer do processo. Para Bomfim (1984), estes problemas precisam de respostas mais rápidas e efetivas, o que torna o tempo para testes e falhas mais curto.

Em virtude disso, os modelos de desenvolvimento de produto surgem para tornar esta atividade mais estruturada, em que, na prática não seguem uma sequência linear. Assim, podem ser considerados como processos desenvolvidos com constantes checagens e retornos, sendo importante promover em cada etapa uma reflexão dos resultados e retroalimentar a etapa seguinte, (ROZENFELD et al., 2006).

Nesta perspectiva, diversos autores como, Bonsiepe (1984), Munari (1998), Baxter (2000), Löbach (2001), Rozenfeld et al. (2006), elaboraram metodologias de projeto de produto a fim de auxiliar a desenvolvimento de produto. Para Baxter (2000), o ponto de partida do processo de design é uma necessidade de mercado ou uma nova ideia que se transforma em uma oportunidade de negócio para dar início à projetação. O modelo proposto pelo autor é dividido em fases e atividades necessárias para o desenvolvimento 
um produto, sendo que a primeira etapa do processo de design compreende o projeto conceitual, em que são geradas alternativas para a solução do problema de design, na segunda etapa, o projeto da configuração, são definidas especificações preliminares acerca da alternativa selecionada, na última etapa, o projeto detalhado, é realizado o detalhamento das especificações até o projeto estar pronto para a fabricação. A figura 1 a seguir, ilustra o processo de design planejado por Baxter (2000).

Figura 1 - Etapas do processo de design.

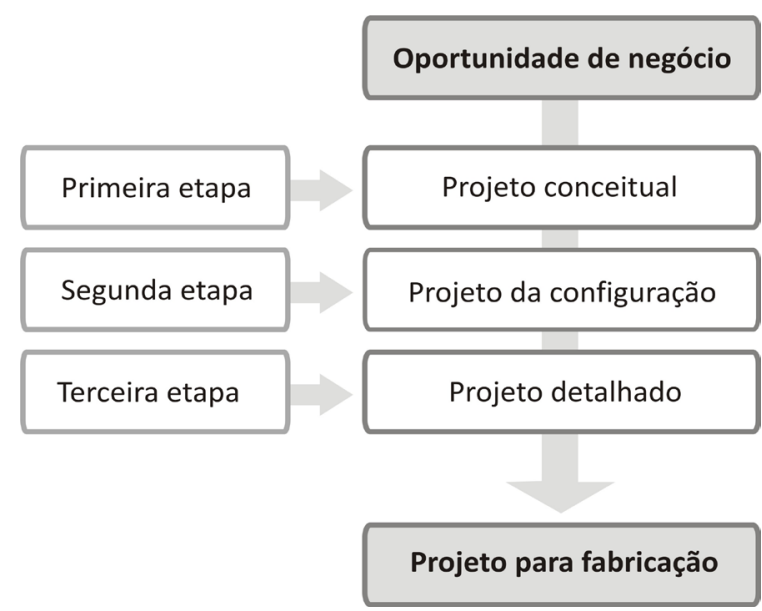

Fonte: Adaptado de Baxter (2000).

Cabe ressaltar que as etapas do processo de design não são estanques e seguidas linearmente, quando for cabível, o projetista pode recuar para as etapas iniciais para realizar ajustes e mudanças necessárias para o projeto em questão. O processo de design, de acordo com Ashby e Johnson (2010, p. 9) está sujeito a diversas influências externas indicadas pelas forças que o cercam. Sendo assim, os autores realizam uma reflexão em torno das forças que permeiam as decisões em um projeto de design. Segundo os autores, o designer procura otimizar o projeto para melhor atender às necessidades do mercado atual, assim é importante o profissional estar ciente dessas forças. Deste modo, os autores sugerem cinco forças, denominadas por eles de insumos dominantes para o processo de design, são eles: a necessidade do mercado, ciência e tecnologia, clima de investimento, sustentabilidade e estética, conforme mostra o esquema da figura 2. 
Figura 2 - Insumos para o processo de design.

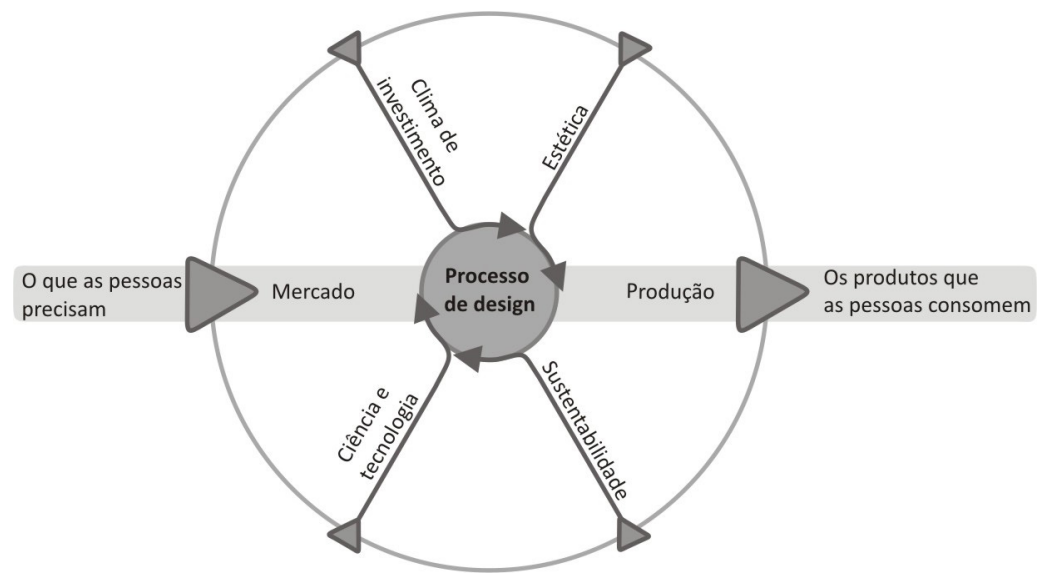

Fonte: Adaptado de Ashby e Johnson (2010).

De acordo com os estudiosos, o círculo central da figura 2 representa o processo de design que recebe forte influência dos insumos. Estes insumos derivam inicialmente da necessidade de mercado, sendo que o crescimento econômico e a natureza das economias de livre-mercado fazem do mercado um grande motivador do design de produto. Além disso, o processo de design é influenciado pelo clima de investimento, por meio das avaliações de lucro e prejuízos esperados, o volume de vendas e a facilidade de fabricação, sendo que isso está relacionado com o desenvolvimento e a comercialização de materiais.

Em relação à estética, os autores comentam que ela abrange os atributos sensoriais dos produtos. Segundo Schneider (2010), a estética está relacionada com a forma, a cor, o material, a superfície, que constituem um objeto no seu aspecto configurativo. Elas tornam compreensível um objeto de uso dando indicações visuais para isso. Assim, a estética é subjetiva e depende de diversos fatores, como: as preferências estéticas, a classe social e a culturalização, a nacionalidade, o sexo, a idade e o hábito.

Para Ashby e Johnson (2010), no que diz respeito à ciência e tecnologia, aquela manifesta novas tecnologias, e a partir disso, podem surgir novos processos e materiais que incitam novas oportunidades para o design de produto.

Assim, os avanços na área de materiais conduzem a progressos no design, que podem originar novos comportamentos, novas experiências, e designs inovadores.

De acordo com Dias (2009), os avanços tecnológicos, na área de materiais e processos, permitem uma melhoria na função prática do produto, e também criam novas possibilidades para que o design melhore as funções 
intangíveis, como, as simbólicas e as estético formais. Desta maneira, com o desenvolvimento da ciência e da tecnologia, novos materiais são introduzidos constantemente na indústria, e eles têm um grande papel na promoção do design de produto. De acordo com Xiong et al. (2008) a introdução e a aplicação de cada novo material pode produzir novos métodos de processamento e manufatura, e também pode propor altos requisitos para o design de produto.

No que se refere à sustentabilidade, esta pode ser definida como "o desenvolvimento que satisfaz às necessidades do presente sem comprometer a capacidade das gerações futuras satisfazerem suas próprias necessidades" (UN DOCUMENTS, 2010). Nesta perspectiva, a partir do conceito de desenvolvimento sustentável é possível considerá-lo como um discurso que visa um ideal para os seres humanos, ou seja, o que ocorre é uma busca pelo desenvolvimento sustentável, em que são criadas estratégias e formas para considerá-lo de maneira mais eficaz, que precisa ser considerado nas esferas econômica, social e ambiental. Assim, o desenvolvimento sustentável, depende do equilíbrio entre essas dimensões, as quais são intrinsecamente interdependentes (UN DOCUMENTS, 2010).

Neste âmbito, o design pode contribuir com a sustentabilidade na medida em que são utilizadas estratégias e métodos para diminuir e/ou contornar problemas de ordem social, econômico e ambiental. De acordo com Manzini e Vezzoli (2002) o desenvolvimento do design para a sustentabilidade significa promover a capacidade do sistema produtivo em proporcionar o bem estar utilizando uma quantidade de recursos ambientais inferior aos níveis atualmente praticados. Assim, os autores enfatizam que "o design para a sustentabilidade pode ser reconhecido como uma espécie de design estratégico" (MANZINI; VEZZOLI, 2002, p. 23), que consiste no projeto de estratégias aplicadas por empresas que estabelecem a prospectiva da sustentabilidade.

\section{A relação entre Design e Materiais}

Os materiais tiveram grande relevância para o desenvolvimento da sociedade, pois por meio deles o homem materializou seus artefatos que o ajudaram na sua sobrevivência. Manzini (1993) observa que no primeiro milhão de anos de sua existência o homem utilizou essencialmente a madeira, pedra, ossos, chifres e couro para construir ferramentas e objetos. Em tempos recentes, surgiram diversos materiais, entre eles os metais, e ao longo de 9.000 anos da história, foram os materiais mais empregados pela humanidade. Com a Revolução Industrial, ocorreram profundas transformações em âmbito cultural, social e econômico, o que tornou acelerada a multiplicidade de materiais 
disponíveis para a produção de produtos. Nesta época, houve o impulso do design devido à necessidade de criação de produtos e o planejamento da produção com base no desenvolvimento em série.

Os materiais desempenham papel essencial no processo de concepção do produto, pois concretizam as ideias, os conceitos e desenhos criados pelos designers. A relação entre materiais e design fica evidente nas compreensões de alguns autores da área, como nas constatações de Ashby e Johnson (2010): "materiais são a matéria de que é feito o design de produto" (ASHBY; JOHNSON, 2010, p. 55), e "interagimos com materiais por intermédio de produtos" (ASHBY; JOHNSON, 2010, p. 81). Gomes (2006, p. 151) também trata desta relação, quando diz que "materiais são componentes físicos que constituem um produto". Em consonância, Ferrante e Walter (2010) argumentam que a ponte de ligação entre a ideia e a produção é o material, que deve ser selecionado e processado até a reprodução física da ideia na forma de produto, levando em consideração as mais diversas condições de uso que o material precisa prever e atender. Para Beylerian e Dent (2007, p. 17) "materiais podem transformar o design, e o design, portanto, tem a força para transformar nossas vidas".

Nesta ótica, os autores supracitados têm visões parecidas no que toca a relação dos materiais com o design, porém diferenciam-se na complexidade. Assim, a relação compreendida por eles centra-se na concretização de uma ideia e, além disso, parece estar associada a melhoria da qualidade de vida dos seres humanos. Outro importante apontamento é a afirmação de Beylerian e Dent (2007) de que os materiais podem ser considerados como uma das fontes mais ricas de inovação, pois segundo eles, podem promover o design inovador.

Neste sentido, no contexto do design, os materiais podem desempenhar diferentes papéis, eles podem definir o leque de funções de produtos, a durabilidade, os custos, entre outros. Ashby e Johnson (2010) relacionam a usabilidade e a ergonomia quando mencionam os seguintes exemplos: objetos pesados podem ficar mais leves com o emprego de ligas de metais leves, polímeros e estruturas de sanduíches preenchidos com espuma, elastômeros podem facilitar a empunhadura e espumas de polímeros permitem superfícies macias ao toque. Sendo assim, os materiais podem auxiliar as soluções de design a cumprirem requisitos propostos no projeto.

No processo de interação do usuário com o material, conforme afirma Dias (2009), cada órgão dos sentidos é capaz de proporcionar diferentes sensações. A autora explica que a modalidade tátil é um importante sistema na interação usuário-produto nos fatores como o conforto, a satisfação e preferências, pois, cada material, com suas propriedades, induz o usuário a uma percepção que é única e particular. Nas palavras da autora, "a utilização estratégica de 
materiais é um dos mais influentes meios de que os designers podem valer-se para comunicar e criar conexões emotivas entre os produtos e seus usuários" (DIAS, 2009, p. 2). Deste modo, a adequada seleção dos materiais pode ser decisiva para que um produto seja eficiente e cumpra as funções com que ele foi projetado.

Nesta perspectiva, os materiais com os quais os produtos são produzidos, são portadores de significados perceptíveis aos usuários, assim, podem influenciar as suas escolhas e preferências. Para Ashby e Johnson (2010), a materialidade cria a personalidade de um produto, pois um material possui atributos percebidos ou associações que os adquire quando aplicado em um produto. $O$ designer pode incorporar diferentes significados em um produto, dependendo do papel que ele desejar que o produto desempenhe. Como exemplo, no caso da madeira, os autores argumentam que é um material natural cujas fibras proporcionam uma textura de superfície própria deste material, ela é tátil, percebida como mais quente em comparação com outros materiais e aparentemente mais macia, possui cheiros característicos e desperta associações com o artesanato. Assim, a madeira é um material bem conhecido, possui características que podem estar associadas a significados atribuídos pelos usuários. Neste sentido, os autores observam que estas características não são apenas estéticas, mas sim, traços que definem uma personalidade, que pode ser revelada pelo designer:

\begin{abstract}
O modo como pensamos em materiais ou em materialidade depende de contexto, cultura, demografia, estilo, tendências e outros. É difícil para as pessoas falarem especificamente sobre os materiais que são usados para fazer as coisas que compram; é tarefa do designer expressar a materialidade de cada objeto. Essa materialidade é o modo como construímos conexões tangíveis entre a marca que é representada, o objeto que é criado e a experiência que é habilitada. Portanto, concluímos: materiais têm uma personalidade intrínseca, embora difícil de se ver até que entre em foco por meio do design de produto, que pretende contar uma história. A história deve ser relevante e significativa para os consumidores, tornando-se real por meio dos materiais e processos de fabricação que nos inspiram e são então especificados. (ASHBY; JOHNSON, 2010, p. 174)
\end{abstract}

Os materiais possuem significados que são percebidos tanto por designers como por usuários. Porém, o tipo de material e a forma como o designer irá empregar o material em um produto, implicará na sua personalidade, e por 
consequência, na percepção dos usuários. Tanto os significados dos materiais, quanto a personalidade dos produtos, dependem do contexto cultural em que são utilizados. Assim, o emprego de materiais no design de produto precisa ser fundamentado também pela cultura, para que os designers consigam atender as necessidades do público-alvo do produto.

Neste contexto, Reis (2003) propõe que a forma de um produto seja determinada, não apenas pelas propriedades físicas do material, mas também, pelo estilo de representação de uma cultura, no sentido de que os diversos valores semânticos e simbólicos tenham a compreensão adequada dos materiais. Deste modo, a forma do produto é influenciada por diversos fatores culturais, como a moda, o prazer, o luxo, novidade, humor e outros, e, sobretudo pelos materiais e processos, (ASHBY; JOHNSON, 2010). Assim, os materiais exercem influências sobre a configuração dos produtos, já que a forma de determinado produto é dependente do material, de suas características tangíveis, que são as propriedades físicas e as intangíveis, que constituem os aspectos sensoriais dos materiais. $O$ autor enfatiza que o bom design é aquele que leva em consideração o uso mais eficiente dos materiais, ou seja, de suas propriedades e da maneira como podem ser conformados. Neste ponto, o designer pode explorar as propriedades favoráveis de determinado material e corrigir as suas deficiências.

Neste intento, a fim de selecionar os materiais mais apropriados para determinada aplicação, é importante que o designer conheça as opções disponíveis, (BEYLERIAN; DENT, 2007). Portanto, entender de materiais é de grande relevância para o processo de design, então, é necessário que o profissional de design tenha uma base sólida de conhecimento sobre eles para que consiga desenvolver produtos eficientes e inovadores.

\section{A seleção de materiais no processo de design}

Segundo Ashby e Johnson (2010) a cada dia a ciência e a tecnologia estão avançando e por consequência surgem diversos novos materiais. Assim, atualmente, são ilimitadas as possibilidades de materiais e a combinação entre eles para a obtenção de diferentes propriedades e desempenhos. De acordo com Manzini (1993), no início do século XX, eram necessários menos de 100 materiais diferentes para a fabricação de um automóvel, hoje o processo exige mais de 4.000 materiais. Assim, devido a grande quantidade de materiais disponíveis para serem empregados em um produto, é necessário selecionar o mais adequado. Segundo Dias (2009), a seleção de materiais ocorre em distintas situações em uma empresa: 
- Na criação de um produto, em que não há limitações sobre o material;

- Na criação de um novo produto para uma empresa que já tenha um processo produtivo que pré-determina certos materiais;

- Modificações ou redesign de um produto visando um melhor desempenho técnico;

- Alteração de materiais para a redução de custos;

- Trabalhar sempre com materiais disponíveis e com custos reduzidos, além de outras situações.

Para o designer, a situação em que não há limitações na escolha dos materiais parece ser a ideal, ou seja, é mais motivador para ele trabalhar com a liberdade para selecionar o material mais apropriado. Porém, na maioria das situações de seleção de materiais este profissional trabalha atrelado a limitações que dirigem para o uso de determinados materiais e processos, como é o caso da maioria das situações citadas anteriormente.

Neste contexto, segundo Kindlein e Busko (2006), independente da situação e do setor ou porte da empresa, é desejável a participação de uma equipe multidisciplinar para proceder à seleção do material no contexto do processo de desenvolvimento do produto. Conforme Dias (2009), tradicionalmente, a seleção de materiais é realizada pela equipe de desenvolvimento da empresa, e em alguns casos ocorre o auxílio de profissionais especializados. Isso ocorre, pelo fato de que a seleção de materiais envolve diversos conhecimentos, desde propriedades técnicas até aspectos estéticos, simbólicos e práticos dos materiais. Deste modo, são necessárias informações de áreas como a engenharia e o design para a escolha efetiva dos materiais.

Para Ashby e Johnson (2010), a seleção de materiais é conduzida por suas características funcionais, como as propriedades e processos, pela estética desejada e por custos de produção. Deste modo, inicialmente na seleção de materiais são definidos os critérios para nortear este processo. Como exemplo, a seleção um material para o solado de um tênis popular tem como objetivo a melhor resistência mecânica possível com custo baixo, para isso, os critérios podem ser: material flexível, resistência ao desgaste e as intempéries, levando em consideração o menor custo, assim, a seleção de materiais deve seguir estes critérios. Desta forma, a seleção de materiais compreende a escolha do material mais adequado conforme os critérios estabelecidos para o desenvolvimento de produto, os quais dependem das especificidades de cada tipo produto. Por exemplo, a joalheria prima pela estética, deste modo, este critério pode nortear 
a seleção de materiais, já os produtos esportivos demandam materiais de alto desempenho, assim, o foco da seleção de materiais pode ser voltada para materiais que possuam esta característica.

Neste contexto, a seleção de materiais está relacionada com o processo de design já nas primeiras etapas, como pode ser visualizado na figura 2. É importante esclarecer que a seleção de materiais não é realizada linearmente durante o processo de design, mas sim, de forma flexível e ajustável ao processo. Deste modo, na primeira etapa do processo de design, a conceitual, o designer possui uma faixa ampla de escolhas, tornando a seleção de materiais de baixa precisão. Nesta fase, os autores argumentam que são necessárias informações genéricas e que todas as opções estão em aberto, podendo ser um polímero para um determinado conceito, um metal para outro, mesmo que a função requerida seja parecida.

Figura 3 - Relação do processo de design com a seleção de materiais.

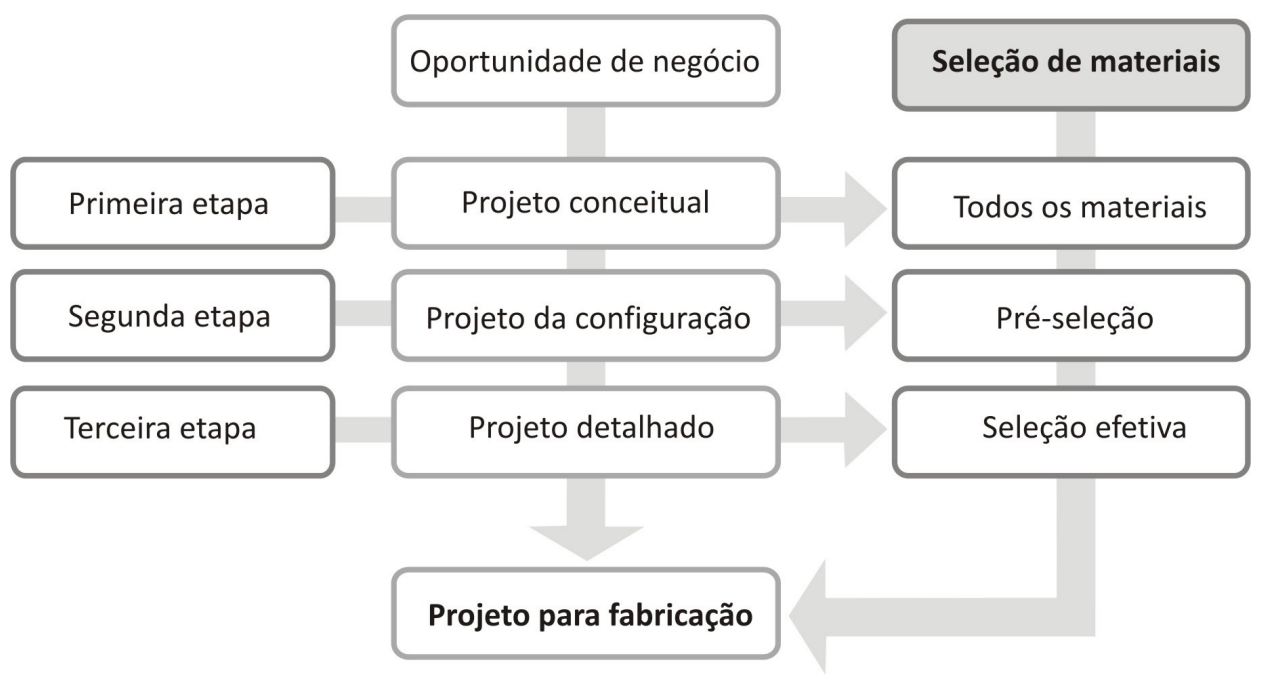

Fonte: adaptado de Sapuan (2001).

$\mathrm{Na}$ próxima etapa de desenvolvimento de produto, o projeto da configuração, são necessárias informações para um subconjunto de materiais em um nível mais alto de precisão e detalhe, sendo assim, nesta etapa é realizada a pré-seleção de materiais seguindo os critérios da seleção de materiais.

A respeito do estágio final do processo de design, o projeto detalhado, é exigido um nível de precisão e detalhe ainda maior acerca dos materiais, assim, é selecionado um ou um número muito pequeno de materiais que sejam mais adequados para determinado projeto.

Como verificado no processo de design, a seleção de materiais está presente desde o início do processo. Assim, é de fundamental importância que designers entendam de materiais, de suas características, propriedades 
técnicas e sensoriais. Para Lesko (2004), além da compreensão do mundo dos materiais, o designer precisa conhecer métodos de fabricação a fim de criar produtos bem sucedidos. Em consonância, Ashby e Johnson (2010) explicam que entender de materiais e de manufatura é fundamental no processo de design.

Outros autores como Ferrante e Walter (2010), enfatizam que o conhecimento na área abre possibilidades para o designer em seu trabalho. Beylerian e Dent (2007) estão em conformidade com os autores citados quando evidenciam que se um designer projetar baseado em um conhecimento limitado sobre os materiais, o projeto será restringido.

\section{CONSIDERAC̄̃̃ES FINAIS}

Os materiais estão diretamente relacionados com o design, exercendo profundas influências sobre as soluções de design. Isso ocorre, devido ao fato de que, principalmente, concretizam ideias dos projetistas, tornando-as tangíveis para as pessoas. Assim, a configuração dos produtos é dependente dos materiais, de seus fatores tangíveis e intangíveis, ou seja, de suas características físicas, definidas por suas propriedades e também por fatores simbólicos, semânticos, estéticos, interligados diretamente com a cultura. Este leque de características próprias influencia a percepção dos produtos pelos usuários, o que pode definir suas preferências e escolhas por determinados produtos. Assim, podem surgir designs inovadores a partir de materiais ou podem ser desenvolvidos novos materiais para atender a determinadas soluções de design.

Os materiais possuem significados que são percebidos tanto por designers como por usuários. Porém, o tipo de material e a forma como o designer irá empregar o material em um produto, implicará na sua personalidade, e por consequência, na percepção dos usuários. Tanto os significados dos materiais, quanto a personalidade dos produtos, dependem do contexto cultural em que são utilizados. O emprego de materiais no design de produto precisa ser fundamentado também pela cultura, para que os designers consigam atender as necessidades do público-alvo do produto.

A seleção de materiais está presente em todas as fases do processo de design, sendo que conforme o projeto avança, a seleção de materiais é refinada até a escolha efetiva do material mais apropriado para o projeto. Cabe ressaltar que a seleção de materiais é influenciada pelo tipo de produto e segue critérios estabelecidos a fim de alcançar a melhor solução. 


\section{REFERÊNCIAS}

ASHBY, M. F.; JOHNSON, K. Materials and design: the art and science of material selection in product design. Amsterdam: Elsevier/ButterworthHeinemann, 2010.

BAXTER, M. Projeto de produto: guia prático para o design de novos produtos. São Paulo: Blucher, 2000.

BEYLERIAN, G. M.; DENT, A. Ultra materials: how materials innovation is chanching the world. Kingdom: Thame \& Hudson, 2007.

BOMFIM, Gustavo Amarante. Metodologia para desenvolvimento de Projetos. Campina Grande: Ed. Universitária, 1984.

BONSIEPE; R. W. Um experimento em projeto de produto: desenho industrial. Brasília: CNPq/Coordenação Editorial, 1984.

CARDOSO, R. Design, cultura material e o fetichismo dos objetos. Revista Arcos (ESDI/UERJ), Rio de Janeiro, v. 1, n. 1, p. 14-39, 1998.

CARDOSO, R. Design, cultura material e o fetichismo dos objetos. Revista Arcos (ESDI/UERJ), Rio de Janeiro, v. 1, n. 1, p. 14-39, 1998.

\section{DIAS, M. R. A. C. Percepção dos materiais pelos usuários: modelo de} avaliação permatus. 2009. Tese (Doutorado em Engenharia e Gestão do Conhecimento) - Programa de Pós-Graduação em Engenharia e Gestão do Conhecimento, Universidade Federal de Santa Catarina, 2009.

FERRANTE, M.; WALTER, Y. A materialização da ideia: noções de materiais para design de produto. Rio de Janeiro: LTC, 2010.

GOMES, F. J. Design do objeto: bases conceituais. São Paulo: Escrituras, 2006.

INTERNATIONAL COUNCIL OF SOCIETIES OF INDUSTRIAL DESIGN. ICSID. Definition of design. 2005. Disponível em: <http://www.icsid. org/about/about/articles31.htm> Acesso em: 20 nov. 2012.

KINDLEIN J. W.; BUSKO, A. M. P. D. Design e engenharia: como fortalecer a pesquisa e promover o diálogo destas áreas do conhecimento? Actas de Diseño: Facultad de Diseño y Comunicación, Palermo, v. 1, p. 155-6, 2006. 
LESKO, J. Design industrial: materiais e processos de fabricação. São Paulo: Edgard Blücher, 2004.

LÖBACH, B. Design Industrial: bases para a configuração dos produtos industriais. São Paulo: Editora Edgard Blücher, 2001.

MANZINI, Ezio. A matéria da invenção. Tradução de Pedro Afonso Dias. Lisboa: Centro Português de Design, 1993.

MANZINI, E.; VEZZOLI, C. O desenvolvimento de produtos sustentáveis: os requisitos ambientais dos produtos industriais. São Paulo: Edusp, 2002.

MUNARI, B. Das coisas nascem coisas. São Paulo: Martins Fontes, 1998.

REIS, A. A. Matéria, forma e função: a influência material no design industrial. 2003. Tese (Doutorado) - Universidade Federal de Santa Catarina, Centro Tecnológico, Programa d e Pós-Graduação em Engenharia de Produção, Florianópolis, 2003.

ROZENFELD, H.; FORCELLINI, F. A.; AMARAL, D. C.; TOLEDO, J. A.; SILVA, S.; ALLIPRANDINI, D. H.; SCALICE, R. K. Gestão de desenvolvimento de produtos: uma referência para a melhoria do processo. São Paulo: Saraiva, 2006.

SANTOS, M. R. Design e cultura: os artefatos como mediadores de valores e práticas sociais. In: QUELUZ, M. L. P. (Org.). Design e cultura. Curitiba: Sol, 2005.

SAPUAN, S. M. A knowledge-based system for materials selection in mechanical engineering design. Materials \& Design, Surrey, v. 22, p. 687695, 2001.

SCHNEIDER, B. Design - uma introdução: o design no contexto social, cultural e econômico. São Paulo: Blücher, 2010.

UN DOCUMENTS. Report of the World Commission on Environment and Development: our common future. 2010. Disponível em: <http://www. un-documents.net/wced-ocf.htm>. Acesso em: 12 dez. 2012.

XIONG, H.; SUN, S.; JIANG, V. Application of modern new materials in product design. IEEE, Kunming, p. 759-764, 2008. 
Recebido em: 24/02/2013.

Aceito em: 19/04/2013. 